\title{
Towards Sustainable Corporate Attraction: The Mediating and Moderating Mechanism of Person-Organization Fit
}

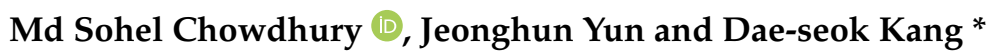 \\ Graduate School of Business Administration, Inha University, Incheon 22212, Korea; sohel@inha.edu (M.S.C.); \\ Yun@inha.edu (J.Y.) \\ * Correspondence: kang0180@inha.ac.kr; Tel.: +82-32-860-7751; Fax: +82-32-866-6877
}

Citation: Chowdhury, M.S.; Yun, J.;

Kang, D.-s. Towards Sustainable

Corporate Attraction: The Mediating and Moderating Mechanism of Person-Organization Fit.

Sustainability 2021, 13, 11998. https:// doi.org/10.3390/su132111998

Academic Editor: Ermanno C. Tortia

Received: 16 September 2021

Accepted: 26 October 2021

Published: 29 October 2021

Publisher's Note: MDPI stays neutral with regard to jurisdictional claims in published maps and institutional affiliations.

Copyright: (c) 2021 by the authors. Licensee MDPI, Basel, Switzerland. This article is an open access article distributed under the terms and conditions of the Creative Commons Attribution (CC BY) license (https:/ / creativecommons.org/licenses/by/ $4.0 /)$.

\begin{abstract}
With the burgeoning "war for talent", attracting the right workforce has become a major key checkpoint for a firm's sustainability. The main purpose of this study was to predict prospective employees' organizational attraction by integrating person-organization $(\mathrm{P}-\mathrm{O})$ fit perceptions and the theory of planned behavior (TPB) into a single framework. Although many studies have reported inconsistent results for the impact of subjective norms and self-efficacy on intention in the TPB framework, adequate empirical research on applicant attraction for this theoretical phenomenon is still unavailable. This may be the first study that examined the mechanism of how and when the TPB model becomes more instrumental with subjective P-O fit perceptions. With a sample of 335 young job seekers in Bangladesh, the study examined the research hypotheses related to the TPB and P-O fit using path analysis with AMOS, a structural equation modeling (SEM) program. The results showed that $\mathrm{P}-\mathrm{O}$ fit partially mediated the relationship between self-efficacy and job search intentions. Observably, P-O fit significantly moderated the relationship between subjective norms and job search intentions in such a way that the impact of subjective norms was stronger for individuals with a lower level of $\mathrm{P}-\mathrm{O}$ fit but slightly weaker for those with a higher level of $\mathrm{P}-\mathrm{O}$ fit. In line with the research findings, some notable theoretical contributions and practical implications for HR professionals have been discussed.
\end{abstract}

Keywords: job seeking; organizational attraction; person-organization fit; theory of planned behavior

\section{Introduction}

Employer branding, a marketing strategy to create an attractive brand for potential candidates, can serve as a key competitive advantage when recruiting, hiring, and retaining Millennials [1,2]. It is plausible in that employer branding helps potential job candidates to assess the compatibility between their own personal values and characteristics and those of the firm in question [3]. Having a vibrant employer brand facilitates a firm to boost its attractiveness by influencing potential candidates' intentions to search for jobs in the firm. Indeed, employer branding ensures a talented pool of job applicants capable of coping with organizational culture quickly and accurately, thereby suggesting a firm's sustainability in an ever-changing business environment [2]. Scholars also presumably argued that influencing the job search intentions of prospective employees is one of the central aims of today's competing firms [4,5]. Failing to do so may lead to the total or partial loss of human capital, thereby resulting in poor corporate sustainability performance. With these lines of argument, Azjen's [6] theory of planned behavior (TPB) is applicable in the studies of job searches in relation to firm attractiveness. The key component of this theory is behavioral intent, which is itself the outcome of a combination of the TPB core variables, i.e., attitude, subjective norms, and self-efficacy [7].

Using the lens of the TPB to structure conceptualization and research focus, many studies have demonstrated a significant influence of job search intention on job search behavior. However, examinations of the paths between the TPB core variables and intention 
have yielded inconsistent findings. While prior studies have consistently highlighted the significant role of attitude in predicting intention, results concerning self-efficacy and subjective norms are less consistent [8]. Although this phenomenon has gained attention in previous research (e.g., $[9,10])$, adequate empirical research on job seeking in relation to organizational attraction from this theoretical perspective is still unavailable. Relatively few studies applied the notion that a variable external to the TPB model may indirectly influence intention and behavior via a potential mediator [11]. Additionally, despite the claim that an external variable may also influence the relative weights that people place on the TPB core variables to form their intentions [12], there are limited empirical studies that have examined this theoretical argument in the job search domain. In this regard, we propose a conceptual model to analyze the mediating and moderating role of personorganization $(\mathrm{P}-\mathrm{O})$ fit perceptions within the TPB framework for predicting the job search intentions of prospective employees.

The $\mathrm{P}-\mathrm{O}$ fit perception refers to individuals' judgment about the compatibility between them and an organization [13]. Along with the TPB core variables, $\mathrm{P}-\mathrm{O}$ fit perception is also an important factor in predicting individuals' intentions and behaviors in various settings, such as job seeking [14]. Considering that perceived compatibility is affected by the perceiver's prior experience, our variables of interest, which include subjective norms and self-efficacy, are likely to construct a potential function regarding this perception. For job seekers, the degree of social pressure to engage in a behavior and the expectation about outcomes in a challenging situation would be key determinants to their career progress, and it may better work under a collectivistic culture, showing greater in-group vigilance [15]. Although there have been many studies that focused on the relationship between fit perceptions and individuals' behavioral intentions (e.g., [16-18]), the role of $\mathrm{P}-\mathrm{O}$ fit perceptions within the TPB framework for predicting job search intentions of future employees has been overlooked. Those studies that accepted the TPB lens failed to capture the realistic aspects of decisions that were made, having been focused too heavily on a Western culture setting. Therefore, the main objective of this study is to investigate whether $\mathrm{P}-\mathrm{O}$ fit mediates the relationship between self-efficacy and job search intention and how it moderates the relationship between subjective norms and such intention, using a sample of Bangladeshi job seekers.

Our study makes several significant contributions to the growing body of knowledge in the related field. First, it extends the previous research, using two core constructs of the TPB (i.e., self-efficacy and subjective norms) and P-O fit in a single framework. Although many studies have reported inconsistent results for the impact of subjective norms and self-efficacy on intention in the TPB framework, adequate empirical research for this theoretical phenomenon is still scarce. With the subjective perception of the $\mathrm{P}-\mathrm{O}$ fit, probing the mechanism of how and when the TPB model becomes more instrumental advances the existing knowledge on career-related actions, including exploiting job opportunities and building a career. Second, this expansive perspective is also valuable in explaining an emergent phenomenon, i.e., employee downsizing. Because employee downsizing has become a common phenomenon during the COVID-19 pandemic, young graduates are becoming more aware of selecting a firm as their potential career destination, and Bangladesh is not an exception. Although this study is not comparative, the theoretical implications of the influence of $\mathrm{P}-\mathrm{O}$ fit on the TPB support a new approach for how employers should meet their potential employees' career needs at the stage of pre-entry beyond the merely reactive mind-set of hiring. Third, through this understanding of situations in which the TPB core variables achieve their improved explanatory power, this study can provide an important foundation for further research into the job-searching process of young job seekers who continue to enter the workforce.

\section{Literature Review and Hypotheses}

An extensive range of literature was reviewed to develop the theoretical framework and research hypotheses for the present study. This section discusses the related literature 
on self-efficacy, subjective norms, and job search intentions, as well as the P-O fit, which was hypothesized as a potential mediating and moderating variable within the TPB framework. The theoretical model that guided this research is shown in Figure 1.

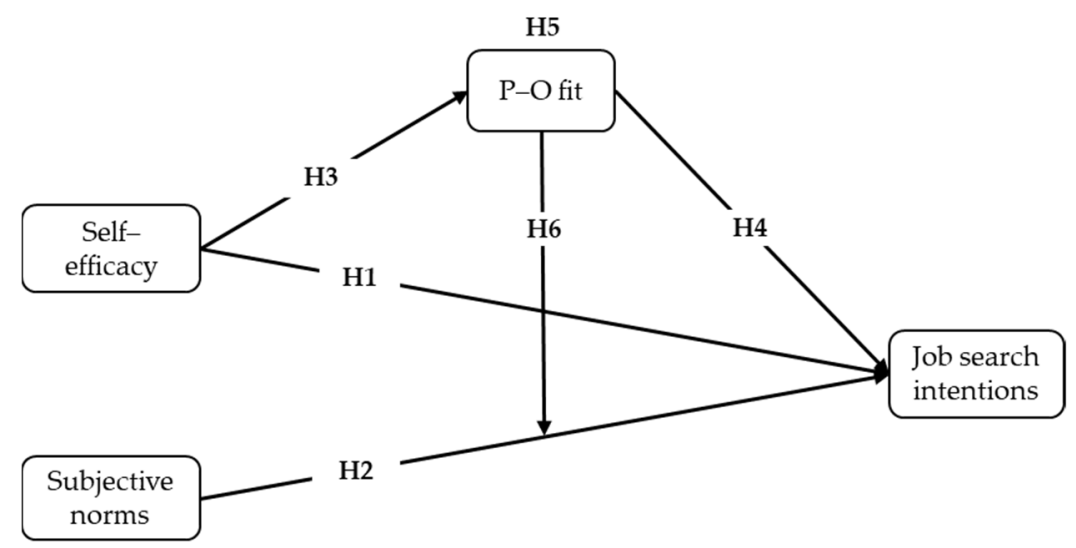

Figure 1. Hypothesized research model.

\subsection{The Theory of Planned Behavior (TPB)}

The TPB is conceptualized as a "complete" theory of behavior and has been used as a "solid" model to examine job search intentions [19]. Perhaps this is due to the premise that behavior is planned and intention is an antecedent toward the planned behavior [6]. When applied to the current study, the TPB states that the immediate antecedent of job search behavior is the intention to look for a job, which in turn is predicted by the extent to which a person has favorable or unfavorable evaluation of the behavior in question (i.e., attitude), the perception of social pressure to align with a particular object or action (i.e., subjective norms), and people's confidence in their ability to perform an action (i.e., perceived controllability). In this framework, TPB provides a satisfactory explanation for intentions and behaviors. Generally, the TPB suggests that the more positive the attitude, subjective norms, and perceived controllability are towards a specific activity, the stronger a person's intention to engage in it.

\subsection{Self-Efficacy and Job Search Intentions}

Of the variables included in the TPB, perceived controllability was the last variable added to the model by Ajzen [20]. This is compatible with Bandura's [21] idea of selfefficacy. In accordance with many prior studies in this field, the variable of perceived controllability has been operationalized as self-efficacy for the current study (e.g., [12,22]). Self-efficacy indicates not only physical powers but also an emotional reaction. The higher the self-efficacy owned by an individual, the more self-confident the person behaves [23]. Several empirical studies showed a significant positive relationship between a person's self-efficacy and job search intention (e.g., $[10,24])$. Furthermore, the studies conducted in collective cultures, such as Asia, have confirmed the positive effects of self-efficacy on job search intention (e.g., $[19,25])$. Based on our theoretical framework and these research results, we developed the first hypothesis as follows:

Hypothesis 1 (H1). Self-efficacy has a significant positive influence on individuals' job search intentions.

\subsection{Subjective Norms and Job Search Intentions}

Subjective norms are understood as the social pressure that an individual perceives when looking for a job. When applied to the current investigation, the TPB suggests that individuals are more likely to form intentions for job searching as they feel more social pressure from their significant others to do so [26]. As such, the study of Carmack and Heiss [27] found significant effects of subjective norms on individuals' job search intentions. 
The influence of social pressure on job search intentions is also culture-specific, in which the individual intention is more likely to be affected by their cultural value perceptions [28]. As noted by Van Hooft and De Jong [12], people high on collectivism were more strongly motivated by subjective norms in forming their job search intentions. This result was also proved valid in China, akin to Bangladesh's collectivist culture [19]. This body of findings has led us to develop the following hypothesis in the context of the present study:

Hypothesis 2 (H2). Subjective norms have a significant positive influence on individuals' job search intentions.

\subsection{The Role of Person-Organization ( $P-O$ ) Fit}

Individuals are differentially compatible with various organizations, and this compatibility has important consequences. As such, a large body of empirical literature provides support to the applicability of the P-O fit to predict job search intentions (e.g., [16,29]). Consistent with past research in the field, the $\mathrm{P}-\mathrm{O}$ fit in the present study addresses the perceived fit, or the degree of an individual's direct judgment of the fit level, rather than the actual fit [30]. Especially in the pre-entry context (before an applicant is hired by an organization), the $\mathrm{P}-\mathrm{O}$ fit refers to prospective employees' assessment of the compatibility between themselves and the work environment of organizations in which they intend to search for jobs. In this view of pre-entry perception, our interest is focused on the potential of the $\mathrm{P}-\mathrm{O}$ fit in facilitating a later judgment about whether objectives have been met. One possible reason for the inconsistencies in the TPB core variables (i.e., subjective norms and self-efficacy in our study) and intention stems from the fact that some information that $\mathrm{P}-\mathrm{O}$ fit perception contains is already present in the TPB model.

\subsection{The Relationship between Self-Efficacy and Perceived P-O Fit}

Job seekers tend to match their abilities to the job tasks in an organization [31]. They are unlikely to pursue a job they are not qualified to perform. They do not expect a job offer when they do not meet the basic task requirements of the job. This indicates that employees with higher self-efficacy find themselves a better fit for organizations and will be more confident to deal with their assigned work [32]. Indeed, a self-efficacy motive may have been antecedent to their decision to pursue a career. Regardless of pre- or postentry, individuals' self-efficacy has a close connection with their subjective fit perceptions (e.g., $[33,34])$. In order for individuals to perceive a good fit for an organization, they must have the necessary KSAs (knowledge, skills, and abilities) or self-confidence in possessing these competencies. As shown in a recent study by Royle [35], self-efficacy enhances $\mathrm{P}-\mathrm{O}$ fit judgments. Consistent with the current literature, we hypothesized that:

Hypothesis 3 (H3). Job seekers' self-efficacy is positively related to their perceived $\mathrm{P}-\mathrm{O}$ fit.

\subsection{The Relationship between Perceived P-O Fit and Job Search Intentions}

In a meta-analysis by Uggerslev et al. [36], the researchers stated that perceived fit is one of the strongest predictors of prospective employees' organizational attraction throughout the recruitment process. As such, previous studies showed that such perception is also one of the most important predictors for shaping job search intention. In a more recent study, Dutta [18] noted that $\mathrm{P}-\mathrm{O}$ fit is more salient in influencing the job search intentions of candidates at the exploration stage compared to the establishment and maintenance stages. Furthermore, for Millennials who may perceive their jobs as a means to another end [37], this personal judgment would be especially critical to have an intent to reach a career goal. Hence, within the TPB framework, we expected a closer relation between perceived $\mathrm{P}-\mathrm{O}$ fit and intentions. Taking these arguments together, we hypothesized that:

Hypothesis 4 (H4). Job seekers' perceived $\mathrm{P}-\mathrm{O}$ fit is positively related to their job search intentions. 


\subsection{P-O Fit as a Mediator between Self-Efficacy and Job Search Intentions}

As mentioned above, the relationship between an employee's $\mathrm{P}-\mathrm{O}$ fit and job search intentions is valid in that $\mathrm{P}-\mathrm{O}$ fit is a function of variables relevant to career, including career success and career satisfaction. Given that the effect of fit perceptions on individual attitudes varies with generations [17], Millennial job seekers who view themselves as competent are likely more intrinsically motivated to engage in job searches through an increased $\mathrm{P}-\mathrm{O}$ fit perception. Along with the direct path between self-efficacy and job search intentions, prospective employees' job-seeking intentions will be optimized when they have compatibility with the organizational environment based on their self-efficacy. That is, we also believe that the level of confidence a job seeker holds affects their $\mathrm{P}-\mathrm{O}$ fit perception, which in turn may influence their intentions to search for jobs in a firm. Based on these premises, we hypothesized that:

Hypothesis $\mathbf{5}$ (H5). The relationship between job seekers' self-efficacy and job search intentions is partially mediated by their perceived $\mathrm{P}-\mathrm{O}$ fit.

\subsection{P-O Fit as a Moderator between Subjective Norms and Job Search Intentions}

In the TPB framework, inconsistent findings indicate that the impact of the two variables can be context-dependent, apart from the potential presence of mediating variables. We here expect the perceived $\mathrm{P}-\mathrm{O}$ fit to play a moderating role in the job seekers' subjective norms-job search intentions relationship. Namely, the potential for social norms to impact job searches may vary with the level of perceived $\mathrm{P}-\mathrm{O}$ fit. As those perceptions of $\mathrm{P}-\mathrm{O}$ fit may eventually become internalized, it is more influential than social norms concerning a particular intent [38]. As a consequence of this trade-off, job seekers' $\mathrm{P}-\mathrm{O}$ fit perceptions might mitigate the degree to which subjective norms affect job search intentions. This is often applicable for the Millennials who are individualistic and narcissistic in nature [39], suggesting that they tend to attribute more value to their subjective $\mathrm{P}-\mathrm{O}$ fit judgement over social orientations of an organization or the perceived pressures imposed on them by the society they belong to. Therefore, we formulated the following hypothesis:

Hypothesis 6 (H6). The perceived $P-O$ fit moderates the relationship between subjective norms and job search intentions such that higher levels of $\mathrm{P}-\mathrm{O}$ fit weaken the positive relationship more than lower levels of $\mathrm{P}-\mathrm{O}$ fit.

\section{Research Method}

The following section provides details on our research method, including the sample and procedures, measures with a description of each of the variables, and data analysis techniques used in this study.

\subsection{Participants and Procedure}

To collect data from the target respondents (i.e., job seekers), a self-administered questionnaire was developed. A pilot study of 18 respondents was conducted to assess the applicability and understandability of measurement items by the target respondents in the context of Bangladesh. The measures seemed usable in the context of this study. After the pilot study, using a non-probability sampling technique that included convenience and snowball sampling, an online survey link was sent to career counselors of different job coaching centers requesting them to forward the link to job seekers. Consistent with past research in this domain (e.g., [40,41]), a list of 20 well-known Bangladeshi firms from diverse industries was provided at the beginning of the questionnaire, asking the respondents to select one of the firms they were familiar with and then to fill out the form.

A total of 351 job seekers participated in the survey. There were 4 missing values found throughout the data-cleaning procedure, and 12 respondents were identified to be unengaged (i.e., the standard deviation of their responses was reported to be zero). For social science research, the remaining sample size $(N=335)$ is suitable for analysis for the 4 focal constructs of the present study [42]. The demographic statistics revealed that most 
participants were male (66.9\%), ranged from 21 to 26 years of age $(84.2 \%)$, were university graduates $(84.8 \%)$, and were unemployed for more than 1 year $(34.6 \%)$.

\subsection{Measures}

For each construct of the present study, measurement items were selected based on previous studies that were reported to be reliable and valid. However, we tailored these items to fit into the context of the present study. Any items identified as potentially problematic were omitted or revised. Responses to each item were scored on five-point Likert scales measuring the respondents' degree of agreement or disagreement with the item in question ( $1=$ strongly disagree; $5=$ strongly agree). For every case, a higher score refers to the higher level of a construct.

\subsubsection{Self-Efficacy}

Respondents' self-efficacy was measured using 5 items selected and adopted from Huang [25] and Arnold et al. [43]. A sample item was "Overall, I feel confident in being able to work for the organization." The reliability estimate in our study was 0.83 .

\subsubsection{Subjective Norms}

Consistent with many studies in this field, this construct was measured using the global scale from Van Hooft and De Jong [12]. One of the two items used was "The most important person in my life thinks that I should search for jobs in the organization." The reliability coefficient was 0.71 .

\subsubsection{Job Search Intentions}

This was measured using 4 items selected based on Van Hooft and De Jong [12] and Huang [25]. A sample item included was "As soon as possible, I really intend to try hard to search for jobs in the organization." The reliability measure was 0.94 .

\subsubsection{Perceived P-O Fit}

This construct was measured using 3 items taken from Cable and De Rue [44] and Saks and Ashforth [45]. A representative item of job seekers' P-O fit was "I think the work environment of the organization is a good match for me." Cronbach's alpha for $\mathrm{P}-\mathrm{O}$ fit perceptions was 0.88 .

\subsubsection{Control Variables}

Respondents' gender, age, and education status were controlled for analysis because they were reported to be influential on job search intentions in previous studies [46]. Unemployment duration was also controlled for the purpose of the present study.

\subsection{Overview of Analyses}

Analyses were performed in three consecutive phases. That is, reliability, validity, and common method variance (CMV) of constructs were measured first, and then wellestablished fit indices were used in order to further assess model fit. Finally, standardized coefficients of the path model were considered for testing the research hypotheses of this study. With AMOS (version 24), all research hypotheses were tested using path analysis. To avoid the multicollinearity problem of the interaction terms of the $\mathrm{P}-\mathrm{O}$ fit and subjective norms with their corresponding main effects on job search intentions, measures were meancentered before calculating the interaction terms [9]. In addition, to check the robustness of the moderating effect of perceived P-O fit, Hayes's [47] PROCESS Macro (Model 1; version 3.4) was used because it is considered a more powerful statistical tool for moderation.

\section{Results}

To test the measurement model, exploratory factor analysis (EFA) and confirmatory factor analysis (CFA) of all items were conducted simultaneously. The EFA results from the 
principal component analysis with varimax rotation extracted four components, having item loadings ranged from 0.65 to 0.86 , considerably over the threshold of 0.50 . Additionally, as expected, all the measurement items were loaded on the relevant factors with no crossloadings. Construct reliability was evaluated using Cronbach's alpha $(\alpha)$ and composite reliability (CR). As shown in Table 1, all CR and Cronbach's $\alpha$ values for each construct of our study exceeded the established threshold of 0.70 , confirming the reliability of the measures. As for construct validity, the factor loadings of the measurement items for each construct ranged from 0.53 to 0.95 and were statistically significant $(p<0.001)$. The average variance extracted (AVE) values for all constructs exceeded the cut-off value of 0.50 , which indicates that convergent validity was obtained. The square root of each construct's AVE was also higher than the respective inter-construct correlation (see Table 2), indicating support for the discriminant validity of all constructs. In addition, various overall fit indices of the measurement model suggested a good fit, as most indices were above or at the recommended thresholds (see Table 3).

Table 1. Reliability and validity statistics.

\begin{tabular}{|c|c|c|c|c|c|c|c|}
\hline \multirow{2}{*}{ Constructs and Items } & \multirow{2}{*}{ CFA Loadings } & \multirow{2}{*}{ CR } & \multirow{2}{*}{ AVE } & \multirow{2}{*}{ MSV } & \multirow{2}{*}{ Cronbach's $(\alpha)$} & \multicolumn{2}{|c|}{ Multicollinearity } \\
\hline & & & & & & Tolerance & VIF \\
\hline Self-efficacy & & 0.83 & 0.51 & 0.49 & 0.83 & 0.74 & 1.35 \\
\hline EFC1 & 0.76 & & & & & & \\
\hline EFC2 & 0.64 & & & & & & \\
\hline EFC3 & 0.72 & & & & & & \\
\hline EFC4 & 0.53 & & & & & & \\
\hline EFC5 & 0.86 & & & & & & \\
\hline Subjective norms & & 0.72 & 0.57 & 0.19 & 0.71 & 0.86 & 1.16 \\
\hline SN2 & 0.75 & & & & & & \\
\hline SN1 & 0.76 & & & & & & \\
\hline $\mathrm{P}-\mathrm{O}$ fit perceptions & & 0.88 & 0.72 & 0.55 & 0.88 & 0.72 & 1.39 \\
\hline POF1 & 0.89 & & & & & & \\
\hline POF2 & 0.85 & & & & & & \\
\hline POF3 & 0.80 & & & & & & \\
\hline Job search intentions & & 0.94 & 0.79 & 0.55 & 0.94 & & \\
\hline INT4 & 0.81 & & & & & & \\
\hline INT3 & 0.85 & & & & & & \\
\hline INT2 & 0.95 & & & & & & \\
\hline INT1 & 0.95 & & & & & & \\
\hline
\end{tabular}

All CFA loadings are significant at $p<0.001$. EFC = self-efficacy; $\mathrm{SN}=$ subjective norms; $\mathrm{POF}=\mathrm{P}-\mathrm{O}$ fit; INT = job search intentions; $\mathrm{MSV}=$ maximum shared variance.

Table 2. Means, standard deviations, and correlations among the variables.

\begin{tabular}{|c|c|c|c|c|c|c|c|c|c|c|}
\hline Variables & $\mathbf{M}$ & SD & 1 & 2 & 3 & 4 & 5 & 6 & 7 & 8 \\
\hline 1. Gender ${ }^{a}$ & 0.33 & 0.47 & 1 & & & & & & & \\
\hline 2. Age ${ }^{b}$ & 0.16 & 0.37 & 0.08 & 1 & & & & & & \\
\hline 3. Education ${ }^{c}$ & 0.85 & 0.36 & -0.07 & 0.09 & 1 & & & & & \\
\hline 4. Unemployment duration $\mathrm{d}$ & 2.42 & 1.05 & $0.14^{* *}$ & $0.19 * *$ & $-0.27^{* *}$ & 1 & & & & \\
\hline 5. Perceived P-O fit & 3.70 & 0.99 & 0.05 & 0.10 & 0.04 & -0.00 & $(0.85)$ & & & \\
\hline 6. Job search intentions & 3.67 & 1.16 & -0.00 & 0.04 & 0.04 & -0.04 & $0.68^{* *}$ & $(0.89)$ & & \\
\hline 7. Subjective norms & 4.18 & 0.72 & 0.03 & -0.01 & 0.02 & -0.01 & $0.34^{* *}$ & $0.33^{* *}$ & $(0.75)$ & \\
\hline 8. Self-efficacy & 3.54 & 0.73 & -0.03 & $0.14^{* *}$ & 0.04 & 0.04 & $0.49^{* *}$ & $0.54^{* *}$ & $0.30^{* *}$ & $(0.71)$ \\
\hline
\end{tabular}

** Correlation is significant at the 0.01 level (2-tailed); ${ }^{a}$ Coded $0=$ male, $1=$ female; ${ }^{b}$ Coded $0=21-26,1=27-32$ (in years); ${ }^{\mathrm{c}}$ Coded $0=$ undergraduate, $1=$ graduate; ${ }^{\mathrm{d}}$ Coded $1=$ less than 6 months, $2=$ more than 6 months but less than 1 year, $3=$ more than 1 year; $\mathrm{n}=335$; Values in the brackets are the square root of AVE of the respective construct.

We further assessed common method bias (CMB) with Harman's single-factor test and a collinearity test based on variance inflation factors (VIF). No dominant factor emerging from the factor analyses was discovered. Likewise, among collinearity statistics in Table 1 , 
all tolerance values were well above $0.10(\mathrm{~min}=0.72)$, and all VIF values were well below $5.00(\max =1.39)$. These diagnostic analyses suggest that CMB is unlikely to be an issue [48]. The means, standard deviations, and correlations of the study variables are presented in Table 2. As predicted, the relationships between self-efficacy, subjective norms, and job search intentions were significant $(\mathrm{r}=0.54, p<0.001 ; \mathrm{r}=0.33, p<0.05)$, respectively. Thus, this provides preliminary support for hypotheses $\mathrm{H} 1$ and $\mathrm{H} 2$. The demographic variables (gender, age, education, and unemployment duration) were used as control variables.

Table 3. Fit indices of measurement model and structural model.

\begin{tabular}{lccc}
\hline \multicolumn{1}{c}{ Model Fit Index } & $\begin{array}{c}\text { Measurement } \\
\text { Model }\end{array}$ & $\begin{array}{c}\text { Structural } \\
\text { Model }\end{array}$ & Cutoff Criteria \\
\hline 1. Chi-square $\left(\chi^{2}\right)$ & 152.85 & 14.13 & \\
2. Degree of freedom $(d f)$ & 71.00 & 5.00 & $\leq 3.00[49]$ \\
3. The ratio of $\chi^{2}$ to $d f\left(\chi^{2} / d f\right)$ & 2.15 & 2.82 & $\leq 0.08[49]$ \\
4. RMSEA & 0.06 & 0.07 & $\leq 0.10[49]$ \\
5. SRMR & 0.04 & 0.04 & $\geq 0.01[49]$ \\
6. PCLOSE & 0.13 & 0.16 & $\geq 0.90[50]$ \\
7. GFI & 0.94 & 0.99 & $\geq 0.90[51]$ \\
8. IFI & 0.97 & 0.98 & $\geq 0.90[52]$ \\
9. CFI & 0.97 & 0.98 & \\
\hline
\end{tabular}

RMSEA = root mean square error of approximation; SRMR = standardized root mean square residual; PCLOSE $=$ p of close fit; GFI = goodness-of-fit index; IFI = incremental fit index; CFI = comparative fit index.

Given that the measurement model fit the data well, the structural model depicting the hypothesized relationships between factors was then evaluated. Control variables were also considered in the path analysis, and the path model explained 53 percent variance $\left(R^{2}\right)$ of job search intentions, indicating the acceptable explanatory power of the model. Table 4 shows the results of hypotheses testing in our study. Of the two TPB components assumed to have a direct relationship, only self-efficacy has a positive influence on job search intentions $(\beta=0.28)$, supporting H1. Contrary to our expectations, the direct relationship between subjective norms and job search intentions was found to be insignificant $(\beta=0.04$, n.s), thus providing no support for $\mathrm{H} 2$.

Table 4. Summary of results for hypotheses testing.

\begin{tabular}{|c|c|c|c|c|c|c|c|c|}
\hline $\begin{array}{l}\text { Hypothesis } \\
\text { No. }\end{array}$ & Effects & $\begin{array}{c}\text { Direct } \\
\text { Effect } \\
(\beta)\end{array}$ & $\begin{array}{l}\text { Indirect } \\
\text { Effect } \\
(\beta)\end{array}$ & $\begin{array}{c}\text { Total } \\
\text { Effect } \\
(\beta)\end{array}$ & $\begin{array}{c}\text { Interaction } \\
\text { Effect } \\
(\beta)\end{array}$ & $p$-Value & $\begin{array}{c}95 \% \text { CI } \\
{[\text { Low, High] }}\end{array}$ & Decisions \\
\hline $\mathrm{H} 1$ & Direct effect of EFC on INT & 0.28 & & & & $<0.001$ & & Supported \\
\hline $\mathrm{H} 2$ & Direct effect of SN on INT & 0.04 & & & & $>0.05$ & & Rejected \\
\hline H3 & Direct effect of EFC on POF & 0.49 & & & & $<0.001$ & & Supported \\
\hline $\mathrm{H} 4$ & Direct effect of POF on INT & 0.52 & & & & $<0.001$ & & Supported \\
\hline H5 & Indirect effect of EFC on INT & & 0.26 & & & $<0.001$ & {$[0.19,0.33]$} & Supported \\
\hline- & Total effect of EFC on INT & & & 0.54 & & $<0.001$ & {$[0.42,0.63]$} & - \\
\hline H6 & Moderating effect of POF & & & & -0.11 & $<0.01$ & {$[-0.18,-0.03]$} & Supported \\
\hline
\end{tabular}

$\mathrm{EFC}=$ self-efficacy; $\mathrm{SN}=$ subjective norms; $\mathrm{POF}=\mathrm{P}-\mathrm{O}$ fit; INT = job search intention.

Next, we evaluated the hypothesis related to the mediating effect of $\mathrm{P}-\mathrm{O}$ fit perceptions. With the correlation between self-efficacy (independent variable) and job search intentions (dependent variable), the relationships between perceived $\mathrm{P}-\mathrm{O}$ fit and self-efficacy ( $\beta=0.49)$ as well as job search intentions $(\beta=0.52)$ were found to be significant $(p<0.001)$, which shows support for the mediation condition [42]. Thus, H3 and H4 were accepted. The indirect effect was further tested using a bootstrapping estimation approach with 5000 resamples [53], and the results indicated a significant indirect coefficient. Both the upper limit and lower limit of confidence intervals of the indirect effect of self-efficacy 
( $\beta=0.26)$ on job search intentions excluded zero, as shown in Table 4. Therefore, H5 for partial mediation was also supported.

Our final analysis concerned the moderating effect of the $\mathrm{P}-\mathrm{O}$ fit on the subjective norms-job search intentions relationship. As Table 4 shows, the interaction outcome of $\mathrm{P}-\mathrm{O}$ fit and subjective norms had a statistically significant negative effect on job search intention ( $\beta=-0.11, p<0.01)$, thus supporting hypothesis H6. To further investigate the robustness of structural results related to the moderating effect, we probed the interaction using the PROCESS macro by Hayes [47]. The conditional values used for the moderator in this study were the means and $\pm 1 \mathrm{SD}$ from the means. Figure 2 depicts the interaction plot to help readers understand the dynamics of the moderating effects of $\mathrm{P}-\mathrm{O}$ fit perceptions. The conditional effect of subjective norms at different values (low vs. high) of the moderator showed that the impact of subjective norms on job search intention is stronger for lower levels of $\mathrm{P}-\mathrm{O}$ fit perceptions and is weaker for higher levels of $\mathrm{P}-\mathrm{O}$ fit perceptions.

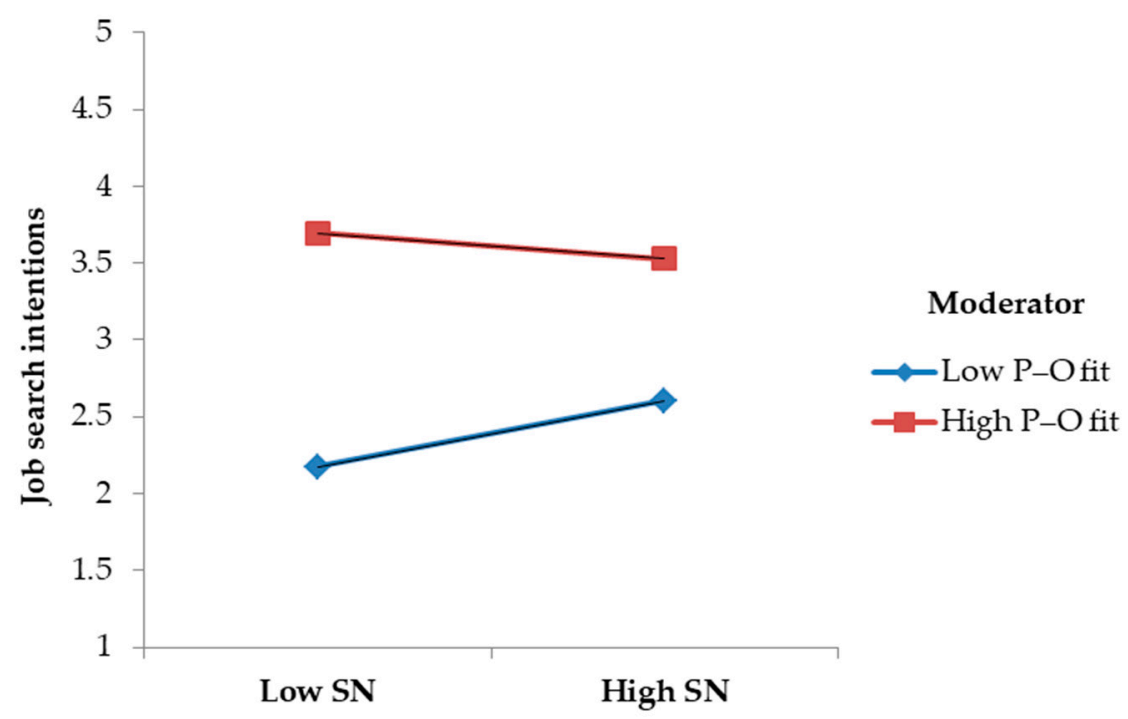

Figure 2. Interaction effects of $\mathrm{P}-\mathrm{O}$ fit and subjective norms on job search intentions.

\section{Discussions}

In the TPB framework, we examined the underlying mechanisms and boundary conditions of the perceived $\mathrm{P}-\mathrm{O}$ fit among the sample of young job seekers in Bangladesh. The results demonstrated that the $\mathrm{P}-\mathrm{O}$ fit can compensate for the weakness in social norms and perceived controllability components of TPB.

As expected, our findings supported the argument that self-efficacy would relate to a prospective employee's job search intentions. This implies that possessing positive self-efficacy is a prerequisite for employment, which may be applicable in diverse contexts, including Asia. Likewise, a notable finding of the present study is that job seekers' $\mathrm{P}-\mathrm{O}$ fit mediated the self-efficacy-job search intentions relationship, suggesting a partial mediating role between the two variables. It seems to indicate that self-efficacy is the strongest indicator to predict job search intentions of unemployed graduates of Bangladesh. Whether directly or indirectly through $\mathrm{P}-\mathrm{O}$ fit perceptions, self-efficacy awareness will allow them to be able to better control the actions and situations they think about.

These results are supportive of many previous studies conducted in other contexts (e.g., [54,55]). It might be because individuals who have high levels of self-efficacy are more likely than others to show resilient outcomes [56]. Considering the changing value and experience of job seekers, it also might be due to the individualistic characteristics of the study samples. However, the study findings are contradictory to a few prior studies (e.g., [12,28]). Although Bangladesh is recognized as a collectivist country, many of today's job seekers are egotistical, thereby supporting the argument that individuals within a single country may have varying cultural orientations [57]. Perhaps job seekers' com- 
petency beliefs could be further reinforced from personal value orientation along with cultural orientations.

Contrary to our hypothesis, there was no significant influence of subjective norms on job search intentions. Perhaps this implies that social norms are no longer important to many people. For instance, Bangladeshi job seekers consider their own values and beliefs to be more important than what others think about them. Like many Millennials [58], they may not be greatly affected by the decisions of their significant others. Another possible reason for this finding could be related to the respondents. Individuals with families are more likely to feel pressure to have a job than individuals without families [59]. Since most respondents were unemployed and were males ranging from 21 to 26 years of age, few would be married under these circumstances in Bangladesh. Hence, the respondents marital status might have also influenced our results. In addition, when considering the economic situation in Bangladesh, it might be unlikely that subjective norms would be a strong predictor of job search intention for our respondents.

Meanwhile, our findings confirmed the moderating role of the P-O fit. Observably, the effect of subjective norms on job search intention was negative for higher levels of $\mathrm{P}-\mathrm{O}$ fit perceptions, whereas the effect was positive for lower levels of $\mathrm{P}-\mathrm{O}$ fit perceptions, indicating the dynamic moderating effects of perceived $\mathrm{P}-\mathrm{O}$ fit within the research model. This result suggests that individuals with lower levels of $\mathrm{P}-\mathrm{O}$ fit perceptions base their job search intention on their significant other's opinions; on the other hand, individuals with higher levels of $\mathrm{P}-\mathrm{O}$ fit perceptions do not care about other's opinions. For today's job seekers, $\mathrm{P}-\mathrm{O}$ fit is an important issue and is thereby less inclined to be affected by social pressure when they perceive themselves a fit for the organization [60]. In other words, in the presence of a high level of $\mathrm{P}-\mathrm{O}$ fit, subjective norms are not influential for shaping Millennial job seekers' organizational attraction.

\subsection{Managerial Implications}

The results of this study have several interesting and useful implications for managers. First, as the mediating and moderating role of $\mathrm{P}-\mathrm{O}$ fit provides insights into the importance of subjective fit, it is essential to be proficient in shaping a fit perception and understanding its working ranges for suited applications. Particularly, recognizing the growing number of Millennials in the global workforce [61,62], managers need to create adequate opportunities and positive expectations regarding their perception of the $\mathrm{P}-\mathrm{O}$ fit. For example, giving a realistic job preview (RJP) in recruitment might contribute to job seekers' perceptions of $\mathrm{P}-\mathrm{O}$ fit, thereby fostering their attraction to an organization as a potential place of work [63]. In addition, recruitment activities providing information in terms of organizational characteristics, norms, and values may enhance a firm's attractiveness to prospective job seekers.

Second, in light of the critical impact of self-efficacy in the realms of job readiness and career advancement, managers need to pay attention to the internal source of action. Individuals with self-efficacy tend to be active [64]. Due to their feelings of responsibility to bring about positive changes within a situation, they are likely to seek opportunities even before joining the workplace, which can help them maintain their human capital and stay competitive. Furthermore, given the indirect effect of self-efficacy in the explanation of the mediating role of $\mathrm{P}-\mathrm{O}$ fit, this mechanism initiated from perceived self-belief is applicable to recruitment and selection practices, including the development of a job description, job advertisement, and interview questions. In the contemporary context of protean and boundaryless careers characterized primarily by psychological mobility, employers are required to commit more hours to understand this self-system that may improve a firm's competitive advantages.

Third, in response to changes in values such as rising individualism and the reformulation of the family structure, management and HR professionals should continually adjust their recruitment related activities. For example, the results of the present study suggest that individualistic traits play a prominent role in predicting job search intention 
in Bangladesh. However, this is in contrast to the belief that in collectivistic countries, subjective norms should be significant among job seekers (e.g., [25]). As such, change management is not an option for today's managers; it is a necessity. They should be sensitive to social change by identifying new HR methods and policies; indeed, there are no absolute principles in HR. Therefore, an organization's recruitment efforts need to be flexible while making staffing strategies for attracting potential talents.

Fourth and in conclusion, companies should become more people-oriented. As a potential employer, a firm can help its future employees to build a unique identity in their eyes and thus encourage them to join, or to stay with, the firm. Job seekers in the Millennial generation are unlikely to search for jobs if they perceive a mismatch between their KSAs and the working environment of a recruiting firm, as demonstrated by the study findings. Indeed, because job seekers have limited access to a firm's information [65], determining the actual fit between the firm's characteristics and their own is challenging, suggesting that a firm should improve its identity and brand awareness among its community stakeholders, especially job seekers [66]. A firm's recruitment channels (e.g., employee referrals, wordof-mouth, social media, and company website) can be utilized as key sources to boost its brand attractiveness and influence fit perceptions, thereby becoming an "employer of choice" among its future human resources.

\subsection{Limitations and Future Research Directions}

The present study results should be interpreted cautiously due to the following three limitations. The first limitation is that this study did not consider the full model of the TPB since the research model lacks one of the TPB core variables (i.e., attitude) and the ultimate dependent variable (i.e., actual behavior). As noted by Sheeran and Webb [67], "people do not always do the things that they intend to do," and the inclusion of an actual behavioral construct could produce different outcomes. Therefore, future researchers may extend the research framework using the full TPB model to predict the actual job pursuit behaviors of unemployed graduates.

Another limitation of our work is that this study adopted a cross-sectional design to collect data only from young job seekers of one country at a single point in time with a self-administered questionnaire. Despite attempts to minimize the magnitude of this problem, readers must be cautious when generalizing this study's findings. In addition, it is undeniable that Generation $\mathrm{Z}$ is the one entering the labor market currently, and the entry of this generation to the workforce prompts changes in HR practices. Hence, future research may explicitly focus on Generation $Z$ of multiple countries to yield more robust results.

Finally, in line with the insignificant effect of subjective norms on job search intention, the study results highlight a need to break subjective norms into different groups (e.g., family, relatives, friends, teachers) to examine whether a certain group has significant effects on job search intention. Such omissions in this study reflect a potential unmeasured variables problem [68]. With this in mind, future research might expand included variables and investigate the motive and long-term consequences of TPB.

Author Contributions: Conceptualization: M.S.C., J.Y. and D.-s.K.; Data curation: M.S.C.; Formal analysis: M.S.C. and J.Y.; Methodology: M.S.C., J.Y. and D.-s.K.; Supervision: D.-s.K.; Writingoriginal draft: M.S.C. and J.Y.; Writing-review and editing: D.-s.K. All authors have read and agreed to the published version of the manuscript.

Funding: This work was supported by Inha University research grant (2021).

Institutional Review Board Statement: Ethical review and approval were waived for this study, due to the lack of sensitive data and the anonymization of all personal information of the people engaged in the study.

Informed Consent Statement: Informed consent was obtained from all subjects involved in the study. 
Data Availability Statement: The data used in this study are available on reasonable request from the corresponding author.

Conflicts of Interest: The authors have no relevant financial or nonfinancial interest to disclose.

\section{References}

1. Santiago, J. The relationship between brand attractiveness and the intent to apply for a job: A millennials' perspective. Eur. J. Manag. Bus. Econ. 2019, 28, 142-157. [CrossRef]

2. Kargas, A.; Tsokos, A. Employer branding implementation and human resource management in Greek telecommunication industry. Adm. Sci. 2020, 10, 17. [CrossRef]

3. Russell, S.; Brannan, M.J. "Getting the rght people on the bus": Recruitment, selection and integration for the branded organization. Eur. Manag. J. 2016, 34, 114-124. [CrossRef]

4. Theurer, C.P.; Tumasjan, A.; Welpe, I.M.; Lievens, F. Employer branding: A brand equity-based literature review and research agenda. Int. J. Manag. Rev. 2018, 20, 155-179. [CrossRef]

5. Kumari, S.; Saini, G.K. Do instrumental and symbolic factors interact in influencing employer attractiveness and job pursuit intention? Career Dev. Int. 2018, 23, 444-462. [CrossRef]

6. Ajzen, I. The theory of planned behavior. Organ. Behav. Hum. Decis. Process. 1991, 50, 179-211. [CrossRef]

7. Hergenrather, K.C.; Rhodes, S.D.; Clark, G.; Clinic, W.-W. Employment-seeking behavior of persons with HIV/AIDS: A theorybased approach. J. Rehabil. 2004, 70, 22-32.

8. Armitage, C.J.; Conner, M. Efficacy of the theory of planned behavior: A meta-analytic review. Br. J. Soc. Psychol. 2001, 40, 471-499. [CrossRef]

9. Song, Z.; Wanberg, C.; Niu, X.; Xie, Y. Action-state orientation and the theory of planned behavior: A study of job search in China. J. Vocat. Behav. 2006, 68, 490-503. [CrossRef]

10. Fort, I.; Pacaud, C.; Gilles, P.Y. Job search intention, theory of planned behavior, personality and job search experience. Int. J. Educ. Vocat. Guid. 2015, 15, 57-74. [CrossRef]

11. Conner, M.; Armitage, C.J. Extending the theory of planned behavior: A review and avenues for further research. J. Appl. Soc. Psychol. 1998, 28, 1429-1464. [CrossRef]

12. Van Hooft, E.A.J.; De Jong, M. Predicting job seeking for temporary employment using the theory of planned behaviour: The moderating role of individualism and collectivism. J. Occup. Organ. Psychol. 2009, 82, 295-316. [CrossRef]

13. Braddy, P.W.; Meade, A.W.; Michael, J.J.; Fleenor, J.W. Internet recruiting: Effects of website content features on viewers' perceptions of organizational culture. Int. J. Sel. Assess. 2009, 17, 19-34. [CrossRef]

14. Kristof, A.L. Person-organization fit: An integrative review of its conceptualizations, measurement, and implications. Pers. Psychol. 1996, 49, 1-49. [CrossRef]

15. Nasby, W.; Hayden, B.; DePaulo, B.M. Attributional bias among aggressive boys to interpret unambiguous social stimuli as displays of hostility. J. Abnorm. Psychol. 1980, 89, 459-468. [CrossRef] [PubMed]

16. Bednarska, M.A. Complementary person-environment fit as a predictor of job pursuit intentions in the service industry. Contemp. Econ. 2016, 10, 27-38. [CrossRef]

17. Bednarska, M.A. Does the effect of person-environment fit on work attitudes vary with generations? Insights from the tourism industry. Int. J. Manag. Econ. 2017, 53, 65-83. [CrossRef]

18. Dutta, D.; Mishra, S.K.; Varma, A. Predictors of job pursuit intention across career stages: A multi-phase investigation. Int. J. Hum. Resour. Manag. 2019, 1-38. [CrossRef]

19. Yizhong, X.; Lin, Z.; Baranchenko, Y.; Lau, C.K.; Yukhanaev, A.; Lu, H. Employability and job search behavior: A six-wave longitudinal study of Chinese university graduates. Empl. Relat. 2017, 39, 223-239. [CrossRef]

20. Ajzen, I. Attitudes, Personality and Behavior, 2nd ed.; McGraw-Hill Education: London, UK, 2005.

21. Bandura, A. Self-efficacy mechanism in human agency. Am. Psychol. 1982, 37, 122-147. [CrossRef]

22. Jung, Y.; Takeuchi, N.; Takeuchi, T. Understanding psychological processes of applicants' job search. Evid.-Based HRM 2016, 4, 190-213. [CrossRef]

23. Kraft, P.; Rise, J.; Sutton, S.; Røysamb, E. Perceived difficulty in the theory of planned behaviour: Perceived behavioural control or affective attitude? Br. J. Soc. Psychol. 2005, 44, 479-496. [CrossRef] [PubMed]

24. Van Hoye, G.; Saks, A.M.; Lievens, F.; Weijters, B. Development and test of an integrative model of job search behaviour. Eur. J. Work Organ. Psychol. 2015, 24, 544-559. [CrossRef]

25. Huang, J.T. Application of planned behavior theory to account for college students' occupational intentions in contingent employment. Career Dev. Q. 2011, 59, 455-466. [CrossRef]

26. Van Hooft, E.A.J.; Born, M.P.; Taris, T.W.; Van der Flier, H. Job search and the theory of planned behavior: Minority-majority group differences in the Netherlands. J. Vocat. Behav. 2004, 65, 366-390. [CrossRef]

27. Carmack, H.J.; Heiss, S.N. Using the theory of planned behavior to predict college students' intent to use linkedIn for job searches and professional networking. Commun. Stud. 2018, 69, 145-160. [CrossRef]

28. Van Hooft, E.A.J.; Born, M.P.; Taris, T.W.; Van der Flier, H.; Blonk, R.W.B. Predictors of job search behavior among employed and unemployed people. Pers. Psychol. 2004, 57, 25-59. [CrossRef] 
29. Phillips, J.M.; Gully, S.M.; Mccarthy, J.E.; Castellano, W.G.; Kim, M.S. Recruiting global travelers: The role of global travel recruitment messages and individual differences in perceived fit, attraction, and job pursuit intentions. Pers. Psychol. 2014, 67, 153-201. [CrossRef]

30. Dineen, B.R.; Ash, S.R.; Noe, R.A. A web of applicant attraction: Person-organization fit in the context of web-based recruitment. J. Appl. Psychol. 2002, 87, 723-734. [CrossRef]

31. Ehrhart, K.H.; Mayer, D.M.; Ziegert, J.C. Web-based recruitment in the Millennial generation: Work-life balance, website usability, and organizational attraction. Eur. J. Work Organ. Psychol. 2012, 21, 850-874. [CrossRef]

32. Peng, Y.; Mao, C. The impact of person-job fit on job satisfaction: The mediator role of self-efficacy. Soc. Indic. Res. 2015, 121, 805-813. [CrossRef]

33. Rottinghaus, P.J.; Van Esbroeck, R. Improving person-environment fit and self-knowledge. In Developing Self in Work and Career: Concepts, Cases, and Contexts; Hartung, P.J., Subich, L.M., Eds.; American Psychological Association: Washington, DC, USA, 2011; pp. 35-52.

34. Wessel, J.L.; Ryan, A.M.; Oswald, F.L. The relationship between objective and perceived fit with academic major, adaptability, and major-related outcomes. J. Vocat. Behav. 2008, 72, 363-376. [CrossRef]

35. Royle, M.T. Can belief in one's capabilities, ultimately, promote career success? Int. J. Manag. Mark. Res. 2019, 12, 1-22.

36. Uggerslev, K.L.; Fassina, N.E.; Kraichy, D. Recruiting through the stages: A meta-analytic test of predictors of applicant attraction at different stages of the recruiting process. Pers. Psychol. 2012, 65, 597-660. [CrossRef]

37. Martin, C.A. From high maintenance to high productivity: What managers need to know about Generation Y. Ind. Commer. Train. 2005, 37, 39-44. [CrossRef]

38. Taufique, K.M.R.; Vaithianathan, S. A fresh look at understanding green consumer behavior among young urban Indian consumers through the lens of theory of planned behavior. J. Clean. Prod. 2018, 183, 46-55. [CrossRef]

39. Twenge, J.M. Generational changes and their impact in the classroom: Teaching generation Me. Med. Educ. 2009, 43, 398-405. [CrossRef]

40. Chowdhury, M.S.; Kang, D. Modeling corporate environmental responsibility perceptions and job-seeking intentions: Examining the underlying mechanism. Sustainability 2021, 13, 6270. [CrossRef]

41. Wang, R.T. Modeling corporate social performance and job pursuit intention: Mediating mechanisms of corporate reputation and job advancement prospects. J. Bus. Ethics 2013, 117, 569-582. [CrossRef]

42. Hair, J.F.; Black, W.C.; Babin, B.J.; Anderson, R.E. Multivariate Data Analysis Prentice Hall; Upper Saddle River: Bergen, NJ, USA, 2009; ISBN 0138132631/9780138132637.

43. Arnold, J.; Loan-Clarke, J.; Coombs, C.; Wilkinson, A.; Park, J.; Preston, D. How well can the theory of planned behavior account for occupational intentions? J. Vocat. Behav. 2006, 69, 374-390. [CrossRef]

44. Cable, D.M.; DeRue, D.S. The convergent and discriminant validity of subjective fit perceptions. J. Appl. Psychol. 2002, 87, 875-884. [CrossRef] [PubMed]

45. Saks, A.M.; Ashforth, B.E. A longitudinal investigation of the relationships between job information sources, applicant perceptions of fit, and work outcomes. Pers. Psychol. 1997, 50, 395-426. [CrossRef]

46. Kanfer, R.; Wanberg, C.R.; Kantrowitz, T.M. Job search and employment: A personality-motivational analysis and meta-analytic review. J. Appl. Psychol. 2001, 86, 837-855. [CrossRef]

47. Hayes, A.F. Introduction to Mediation, Moderation and Conditional Process Analysis: A Regression-Based Approach; The Guilford Press: New York, NY, USA, 2018; ISBN 9781462534654.

48. Kutner, M.H.; Nachtsheim, C.J.; Neter, J. Applied Linear Regression Models; McGraw-Hill: New York, NY, USA, 2004.

49. Hu, L.T.; Bentler, P.M. Cutoff criteria for fit indexes in covariance structure analysis: Conventional criteria versus new alternatives. Struct. Equ. Model. 1999, 6, 1-55. [CrossRef]

50. Roy, R.; Das, N. A critical comparison of factors affecting science and technology students' entrepreneurial intention: A tale of two genders. Int. J. Educ. Vocat. Guid. 2020, 20, 49-77. [CrossRef]

51. Kim, H.; Kang, D.; Lee, S.; McLean, G. Career commitment as a mediator between organization-related variables and motivation for training and turnover intentions. J. Career Dev. 2016, 43, 130-144. [CrossRef]

52. Shin, I.; Hur, W.M.; Kang, S. Employees' perceptions of corporate social responsibility and job performance: A sequential mediation model. Sustainability 2016, 8, 493. [CrossRef]

53. Preacher, K.J.; Hayes, A.F. Asymptotic and resampling strategies for assessing and comparing indirect effects in multiple mediator models. Behav. Res. Methods 2008, 40, 879-891. [CrossRef]

54. Zikic, J.; Saks, A.M. Job search and social cognitive theory: The role of career-relevant activities. J. Vocat. Behav. 2009, 74, 117-127. [CrossRef]

55. Lin, H.F. Applicability of the extended theory of planned behavior in predicting job seeker intentions to use job-search websites. Int. J. Sel. Assess. 2010, 18, 64-74. [CrossRef]

56. Werner, E.E.; Smith, R.S. Overcoming the Odds: High Risk Children from Birth to Adulthood; Cornell University Press: New York, NY, USA, 1992; ISBN 0801480183.

57. Van Hooft, E.A.J.; Born, M.P.; Taris, T.W.; van der Flier, H. The cross-cultural generalizability of the theory of planned behavior: A study on job seeking in the Netherlands. J. Cross. Cult. Psychol. 2006, 37, 127-135. [CrossRef] 
58. Pînzaru, F.; Vătămănescu, E.-M.; Mitan, A.; Săvulescu, R.; Vițelar, A.; Noaghea, C.; Bălan, M. Millennials at work: Investigating the specificity of generation Y versus other generations. Manag. Dyn. Knowl. Econ. 2016, 4, 173-192.

59. Van Hooft, E.A.J.; Born, M.P.; Taris, T.W.; van der Flier, H. Predictors and outcomes of job search behavior: The moderating effects of gender and family situation. J. Vocat. Behav. 2005, 67, 133-152. [CrossRef]

60. Sekiguchi, T. Toward a dynamic perspective of person-environment fit. Osaka Keidai Ronshu 2004, 55, 177-190.

61. Carballo-Penela, A.; Ruzo-Sanmartín, E.; Sousa, C.M.P. Influence of business commitment to sustainability, perceived value fit, and gender in job seekers' pursuit intentions: A cross-country moderated mediation analysis. Sustainability 2020, $12,4395$. [CrossRef]

62. Carballo-Penela, A. Enhancing social sustainability at a business level: Organizational attractiveness is higher when organizations show responsibility towards employees. Bus. Strateg. Dev. 2019, 2, 372-383. [CrossRef]

63. Firfiray, S.; Mayo, M. The lure of work-life benefits: Perceived person-organization fit as a mechanism explaining job seeker attraction to organizations. Hum. Resour. Manag. 2017, 56, 629-649. [CrossRef]

64. Lu, C.Q.; Siu, O.L.; Cooper, C.L. Managers' occupational stress in China: The role of self-efficacy. Pers. Individ. Dif. 2005, 38, 569-578. [CrossRef]

65. Kedharnath, U.; Shore, L.M.; Dulebohn, J.H. Organizational trust among job seekers: The role of information-seeking and reciprocation wariness. Int. J. Sel. Assess. 2020, 28, 351-363. [CrossRef]

66. Tanwar, K.; Kumar, A. Employer brand, person-organisation fit and employer of choice. Pers. Rev. 2019, 48, 799-823. [CrossRef]

67. Sheeran, P.; Webb, T.L. The intention-Behavior gap. Soc. Personal. Psychol. Compass 2016, 10, 503-518. [CrossRef]

68. James, L.R. Testing hypotheses in the context of the unmeasured variables problem. Hum. Resour. Manag. Rev. 1991, 1, $273-291$. [CrossRef] 